
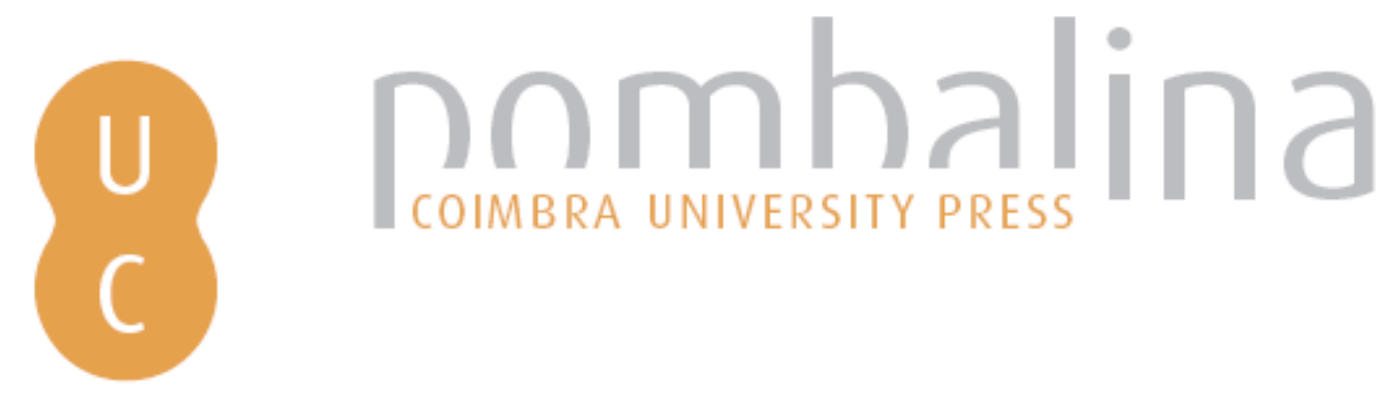

\title{
Utilização de geotecnologias no mapeamento digital de uso da terra e cobertura vegetal para o subsídio do zoneamento ambiental no parque estadual da serra da Tiririca (Peset, Brasil)
}

Autor(es): $\quad$ Santos Junior, W. M.

Publicado por: Imprensa da Universidade de Coimbra

URL persistente:

URI:http://hdl.handle.net/10316.2/31449

DOI:

DOI:http://dx.doi.org/10.14195/978-989-26-0531-9_21

Accessed : $\quad$ 26-Apr-2023 11:22:40

A navegação consulta e descarregamento dos títulos inseridos nas Bibliotecas Digitais UC Digitalis, UC Pombalina e UC Impactum, pressupõem a aceitação plena e sem reservas dos Termos e Condições de Uso destas Bibliotecas Digitais, disponíveis em https://digitalis.uc.pt/pt-pt/termos.

Conforme exposto nos referidos Termos e Condições de Uso, o descarregamento de títulos de acesso restrito requer uma licença válida de autorização devendo o utilizador aceder ao(s) documento(s) a partir de um endereço de IP da instituição detentora da supramencionada licença.

Ao utilizador é apenas permitido o descarregamento para uso pessoal, pelo que o emprego do(s) título(s) descarregado(s) para outro fim, designadamente comercial, carece de autorização do respetivo autor ou editor da obra.

Na medida em que todas as obras da UC Digitalis se encontram protegidas pelo Código do Direito de Autor e Direitos Conexos e demais legislação aplicável, toda a cópia, parcial ou total, deste documento, nos casos em que é legalmente admitida, deverá conter ou fazer-se acompanhar por este aviso.

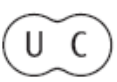





\title{
UTILIZAÇÃO DE GEOTECNOLOGIAS NO MAPEAMENTO DIGITAL DE USO DA TERRA E COBERTURA VEGETAL PARA O SUBSÍDIO DO ZONEAMENTO AMBIENTAL NO PARQUE ESTADUAL DA SERRA DA TIRIRICA (PESET, BRASIL)
}

\author{
USE OF GEOTECHNOLOGIES ON DIGITAL MAPPING \\ IN LAND AND PLANT COVER AS A CONTRIBUTION \\ TO THE ENVIRONMENTAL ZONING IN THE STATE PARK \\ OF SERRA OF TIRIRICA (PESET, BRAZIL)
}

W. M. Santos Junior ${ }^{1}$

\begin{abstract}
Resumo - No Brasil, dentre as áreas protegidas e regulamentadas por lei estão as denominadas Unidades de Conservação (UC) e são definidas assim por possuírem características ambientais importantes na manutenção dos ciclos naturais, demandando regimes especiais de preservaçáo, conservação ou exploração racional dos seus recursos. O Parque Estadual da Serra da Tiririca (PESET), criado pela Lei 1.901, de 29 de novembro de 1991, localizado entre os municípios de Niterói e Maricá no Estado do Rio de Janeiro, Brasil, enquadra-se na categoria de UC de Proteção Integral abrigando uma extensa faixa de Mata Atlântica em seus limites. Para a presente pesquisa foi feita uma classificação de Uso da Terra e Cobertura Vegetal, refinada por pesquisas feitas através do trabalho de campo, que subsidiou a elaboração da proposta de Zoneamento Ambiental para o parque. O estudo feito através da modelagem computacional do PESET apresenta o emprego das técnicas amplamente utilizadas no monitoramento ambiental, sendo úteis aos profissionais destinados à gestáo e aos tomadores de decisão no âmbito das políticas públicas relacionadas à gestão ambiental de Unidades de Conservação.
\end{abstract}

Palavras-chave - Geotecnologia, Uso da Terra, PESET, Zoneamento Ambiental.

Abstract - In Brazil, among the protected areas regulated by law are the so called Conservation Units (UC) which are so defined for having environmental characteristics

${ }^{1}$ Universidade Estadual do Rio de Janeiro; wilson.messias@gmail.com 
important in maintaining natural cycles, requiring special arrangements for preservation, conservation and rational exploration of resources. The State Park of Serra da Tiririca (PESET), created by law1901 of November 29, 1991, located between the cities of Niterói and Maricá in the State of Rio de Janeiro, Brazil, falls under the category of UC full protection harboring an extensive stretch of Atlantic Forest within its boundaries. In the presented research we made a classificationof land use and land cover, refined by search done through field work, which contributed to the drafting of the proposed environmental zoning for the park. The study done by computer modeling of the PESET shows the use of techniques widely applied in environmental monitoring which are useful to management professionals and decision-makers in public policies related to environmental management of protected areas.

Keywords - Geotechnology, Land Use, PESET, Environmental Zoning

\section{1 - Introdução}

O Parque Estadual da Serra da Tiririca (PESET), localizado entre os municípios de Niterói e Maricá, enquadra-se na categoria de unidade de conservação, mais precisamente como Área de Proteção Integral por abrigar uma extensa faixa de Mata Atlântica em bom estado de conservaçáo (RODRIGUES, 2004). As açóes para proteçáo da Serra da Tiririca tiveram início em meados da década de 80 , a partir de iniciativas populares.

A Serra da Tiririca está inserida entre os municípios de Niterói e Maricá no Estado do Rio de Janeiro (Fig. 1). Em Niterói insere-se nos bairros do Engenho do Mato, Itaipu, Itacoatiara e Várzea das Moças totalizando uma área de aproximadamente 1.205,48 hectares (59\%). No município de Maricá insere-se em Itaipuaçu (Distrito de Inoã) abrangendo uma área de 855,40 hectares (41\%). Com uma área total de 2.252,81 hectares, inicia-se entre as praias de Itacoatiara e Itaipuaçu estendendo-se longitudinalmente até a Rodovia Amaral Peixoto (RJ-106). 


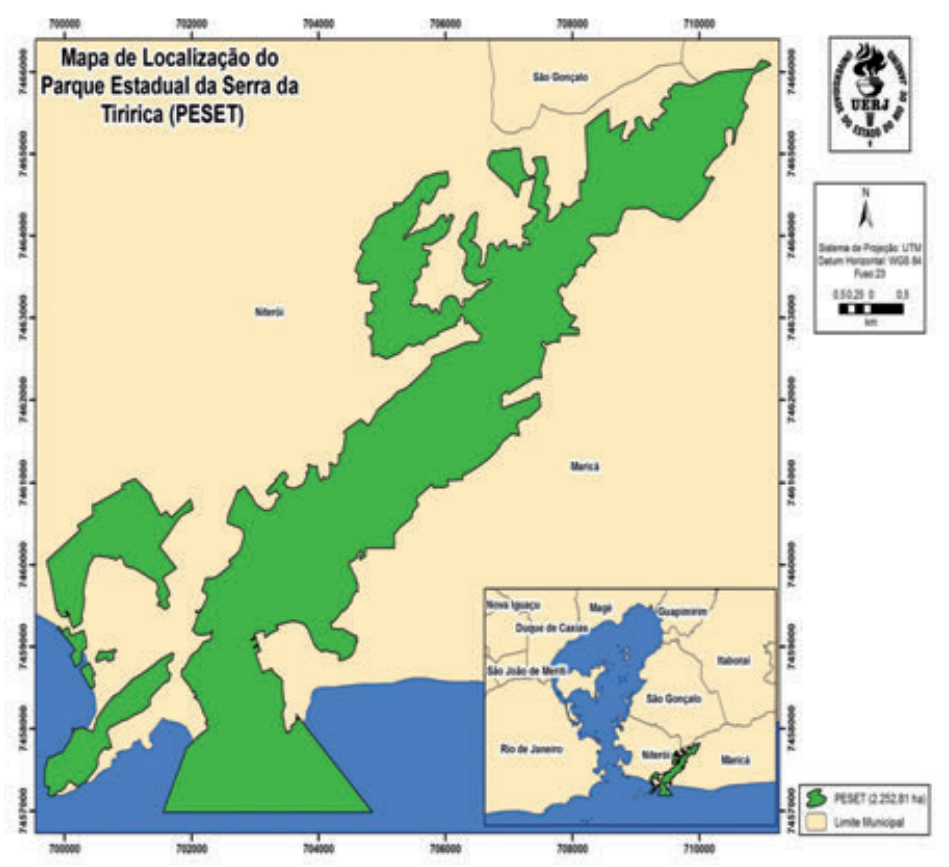

Fig.1 - Localização Geográfica da Área de Pesquisa.

A região da Serra da Tiririca é rica em vestígios e sítios arqueológicos, principalmente em Itaipu onde existem importantes sambaquis, tendo registros da existência de populaçôes pré-históricas de tradiçôes variadas que se sucederam no local (BELTRÃO, 1978).

\section{2 - Sistema de informação geográfica e meio ambiente}

Os Sistemas de Informação Geográfica (SIG) caracterizam-se por um conjunto de ferramentas computacionais utilizados para se obter uma melhor compreensão ou caracterização dos fenômenos que ocorrem no espaço geográfico (BINS et al., 2000).

A sua capacidade de reunir e processar uma grande quantidade de informaçóes acerca daquilo que se objetiva analisar, torna o SIG uma ferramenta importante para o monitoramento ambiental (CÂMARA, 1996), sendo uma componente chave para estudos e trabalhos de pequeno, médio e longo prazo realizado em diferentes campos do conhecimento (PINA et al., 2000), dentre eles em unidades de conservação da natureza.

Para o presente trabalho está sendo desenvolvido um banco de dados geográfico multiescalar composto uso da Terra e cobertura vegetal obtido a partir de imagens Ikonos e Worldview (2007 e 2011 respectivamente) que subsidiaram o mapeamento do zoneamento ambiental da Serra da Tiririca e outros temas oriundos do cruzamento das informaçôes espaciais, onde foram indicados os percentuais de uso para cada tema. 


\section{3 - Classificação das imagens Ikonos e Worldview}

Através da classificação das imagens pode-se observar e compreender a importância do Parque Estadual da Serra da Tiririca no contexto de Unidade de conservação da Natureza no Estado do Rio de Janeiro. A análise dos resultados apresentados foi feita de forma quantitativa uma vez que os sensores apresentam características diferentes. $\mathrm{O}$ mais importante foi perceber que mesmo se tratando de sensores distintos e imagens adquiridas em anos diferentes, pode-se comprovar o quantitativo de Floresta Ombrófila Densa em estágio avançado de conservação encontrado no PESET (SANTOS et al., 1998). Os mapas a seguir demonstram esse quantitativo que reforça a categoria de proteçáo integral da unidade (SNUC, 2000), bem como seu papel relevante na conservação da natureza existente na área da pesquisa. Os mapas temáticos (Fig. 2a e 2b) apresentam a classificação supervisionada por crescimento de regiôes obtidas pelo software de Sistema de Processamento de Informaçôes Georreferenciadas SPRING (produzido pelo Instituto de Pesquisas Espaciais - INPE/ Brasil) posteriormente refinadas no software ArcGIS produzido pela Esri.

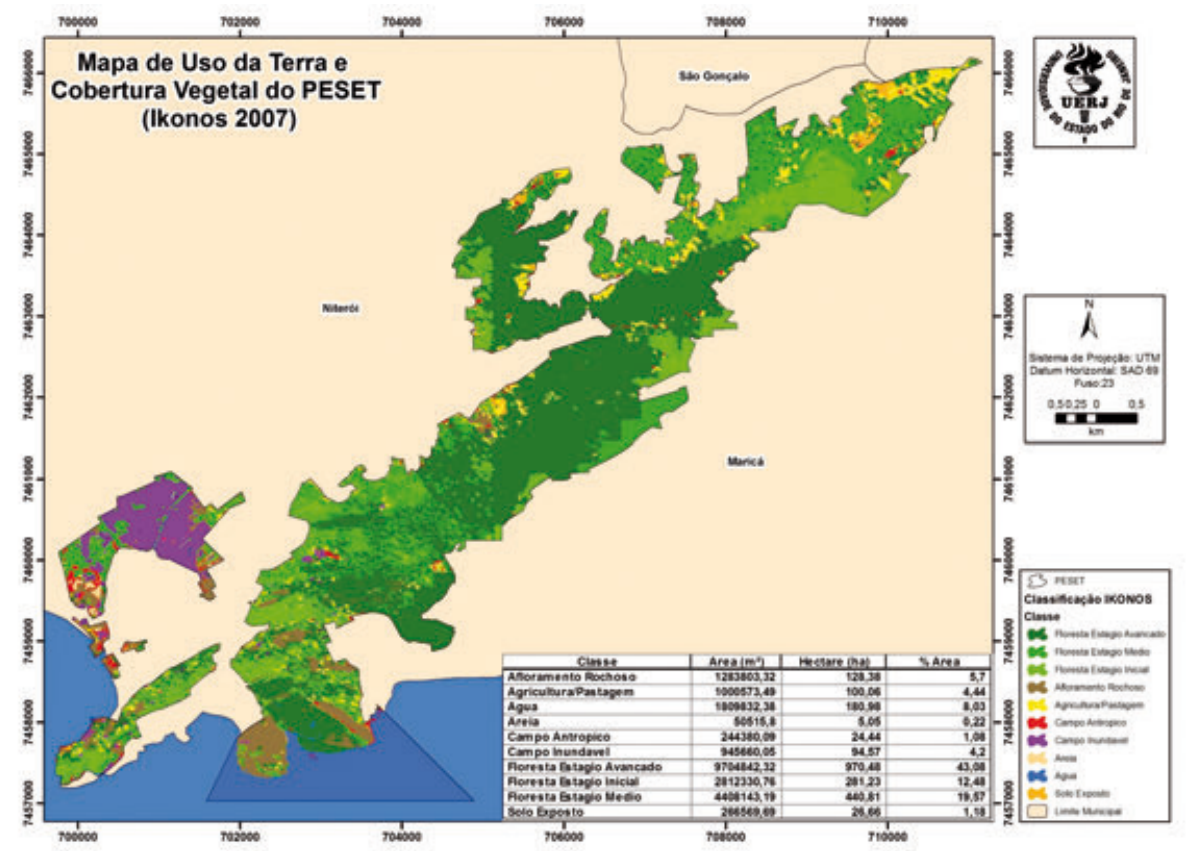

Fig.2a - Classificação supervisionada Ikonos. 


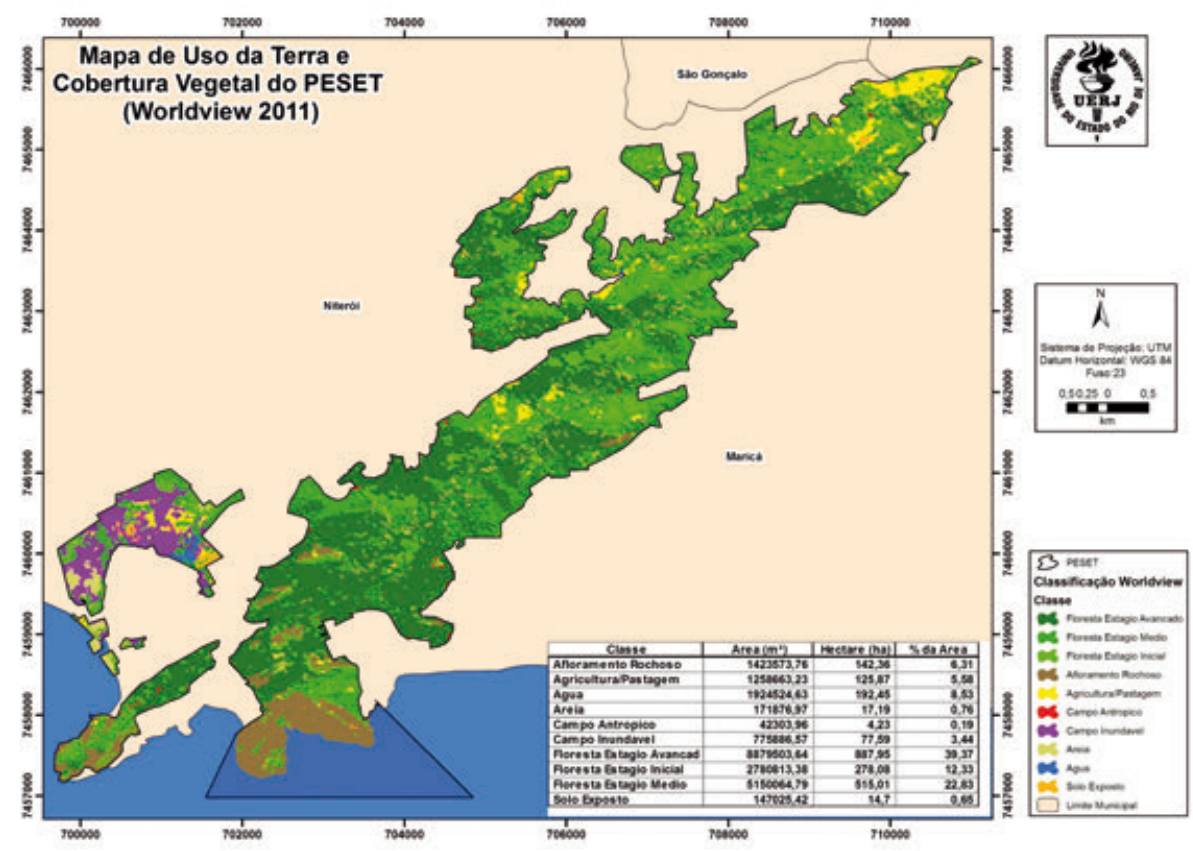

Fig.2b - Classificação supervisionada Worldview.

Fazendo-se uma comparação quantitativa entre as classes mapeadas em cada imagem pode-se avaliar que entre os anos de 2007 e 2011 tivemos algumas alteraçóes conforme indicado (tabela 1 e tabela 2) a seguir:

Tabela 1 - Valores obtidos na classificaçấo da imagem IKONOS de 2007.

\begin{tabular}{ccc}
\hline CLASSE & HECTARE (ha) & $\%$ ÁREA \\
\hline Afloramento Rochoso & 128,38 & 5,70 \\
Agricultura/Pastagem & 100,06 & 4,44 \\
Água & 180,98 & 8,03 \\
Areia & 5,05 & 0,22 \\
Campo Antrópico & 24,44 & 1,08 \\
Campo Inundável & 94,57 & 4,20 \\
FEA & 970,48 & 43,08 \\
FEI & 281,23 & 12,48 \\
FEM & 440,81 & 19,57 \\
Solo Exposto & 26,66 & 1,18 \\
TOTAL & 2255,42 & 100,00 \\
\hline
\end{tabular}


Tabela 2 - Valores obtidos na classificação da Imagem Worldview de 2011.

\begin{tabular}{ccc}
\hline CLASSE & HECTARE (ha) & \% AREA \\
\hline Afloramento Rochoso & 142,36 & 6,31 \\
Agricultura/Pastagem & 125,87 & 8,58 \\
Água & 192,45 & 0,76 \\
Areia & 17,19 & 0,19 \\
Campo Antrópico & 4,23 & 3,44 \\
Campo Inundável & 77,59 & 39,37 \\
FEA & 887,95 & 12,33 \\
FEI & 278,08 & 22,83 \\
FEM & 515,01 & 0,65 \\
Solo Exposto & 14,70 & 100,00 \\
TOTAL & $2.255,42$ & \\
\hline
\end{tabular}

A partir da diferença entre as duas tabelas pode-se avaliar em termos quantitativos o quanto cada classe obteve alteração positiva ou negativa (tabela 3) em relação ao uso da terra e cobertura vegetal.

Tabela 3 - Diferença quantitativa das classes de Uso da Terra e cobertura vegetal entre os anos de 2007 e 2011.

\begin{tabular}{ccc}
\hline CLASSE & HECTARE (ha) & \% AREA \\
\hline Afloramento Rochoso & 13,98 & 0,61 \\
Agricultura/Pastagem & 25,81 & 1,14 \\
Água & 11,47 & 0,50 \\
Areia & 12,14 & 0,54 \\
Campo Antrópico & $-20,21$ & $-0,90$ \\
Campo Inundável & $-16,98$ & $-0,76$ \\
FEA & $-82,53$ & $-3,71$ \\
FEI & $-3,15$ & $-0,16$ \\
FEM & 74,19 & 3,27 \\
Solo Exposto & $-11,95$ & $-0,53$ \\
\hline
\end{tabular}

Avaliando-se as tabelas acima, podemos comprovar que tanto nos anos de 2007 quanto em 2011 o quantitativo de Floresta Ombrófila Densa em Estágio Avançado (FEA) de Conservação encontra-se com o valor bem acima de qualquer outra classe de uso da Terra e cobertura vegetal, ressaltando um dos mais importantes objetivos da criaçáo do parque que é o de proteção dos remanescentes de floresta em bom estado 
de conservação. Os estágios de Floresta em Estado Inicial (FEI) e intermediário de conservação também superam as demais classes demonstrando a relevância da preservação da unidade. Dentre as demais classes vale ressaltar o decréscimo do valor da classe "campo antrópico (área urbana)” devido à política de desapropriação de algumas construçóes que se encontravam nos limites da unidade.

$\mathrm{Na}$ tabela da diferença pode comprovar que algumas classes como a (FEA) apresentaram um pequeno decréscimo da sua área em termos absolutos enquanto a Floresta Estágio médio (FEM) obteve um aumento significante entre 2007 a 2011.

\section{4 -Proposta de Zoneamento Ambiental para o Parque Estadual da Serra da Tiririca (PESET)}

Seguindo a proposta de plano de manejo (INEA, 2010) os parques podem conter as zonas de preservação e conservação, áreas de visitação, uso especial, uso conflitante, áreas de recuperação e histórico-cultural. A zona de preservação deve, preferencialmente, estar localizada no centro da UC, e estar sempre protegida pela zona de conservaçáo. A área de uso especial conterá as edificaçôes para a administração e poderá incluir uma faixa na periferia de toda a UC, destinada a acessos. A área de visitação deverá também estar localizada na periferia da UC, de maneira a levar o visitante e o pesquisador a desfrutar de seus atributos. Tanto a área de uso especial, quanto a de visitação devem estar localizadas somente na zona de conservação. A área histórico-cultural poderá ou não existir, em razão dos atributos específicos de ordem histórica, religiosa, cultural, arqueológica e paleontológica que ocorram na UC (INEA, 2010). As áreas de recuperação e de uso conflitante também terão localização aleatória em razão da existência de condiçôes que levem à necessidade de sua implantação. Essas três últimas devem estar localizadas somente na zona de preservação. Nessa pesquisa optou-se em contemplar cinco das sete categorias para a proposta de zoneamento ambiental em parques estaduais.

As classes de uso da Terra e cobertura vegetal foram agrupadas de acordo com a sua relevância ambiental e distribuídas entre as zonas (tabela 4), como demonstrado a seguir:

Tabela 4 - Agrupamento das classes para o zoneamento ambiental.

\begin{tabular}{|c|c|c|c|}
\hline ZONEAMENTO & CLASSE & HECTARE (ha) & \% da ÁREA \\
\hline Área de Recuperação & $\begin{array}{c}\text { Agricultura/Pastagem } \\
\text { Areia } \\
\text { Solo Exposto }\end{array}$ & 157,76 & 7,00 \\
\hline Área de Uso Conflitante & Campo Antrópico & 4,23 & 0,19 \\
\hline Área de Uso Especial & Afloramento Rochoso & 142,36 & 6,31 \\
\hline Zona de Conservação & $\begin{array}{l}\text { Floresta Estágio Inicial } \\
\text { Floresta Estágio Médio }\end{array}$ & 793,09 & 35,16 \\
\hline Zona de Preservação & $\begin{array}{c}\text { Água } \\
\text { Campo Inundável } \\
\text { Floresta Estágio Avançado }\end{array}$ & $1.157,99$ & 51,34 \\
\hline
\end{tabular}


O mapa a seguir ilustra a proposta de Zoneamento ambiental (Fig.3) para o Parque Estadual da Serra da Tiririca elaborado nesta pesquisa:

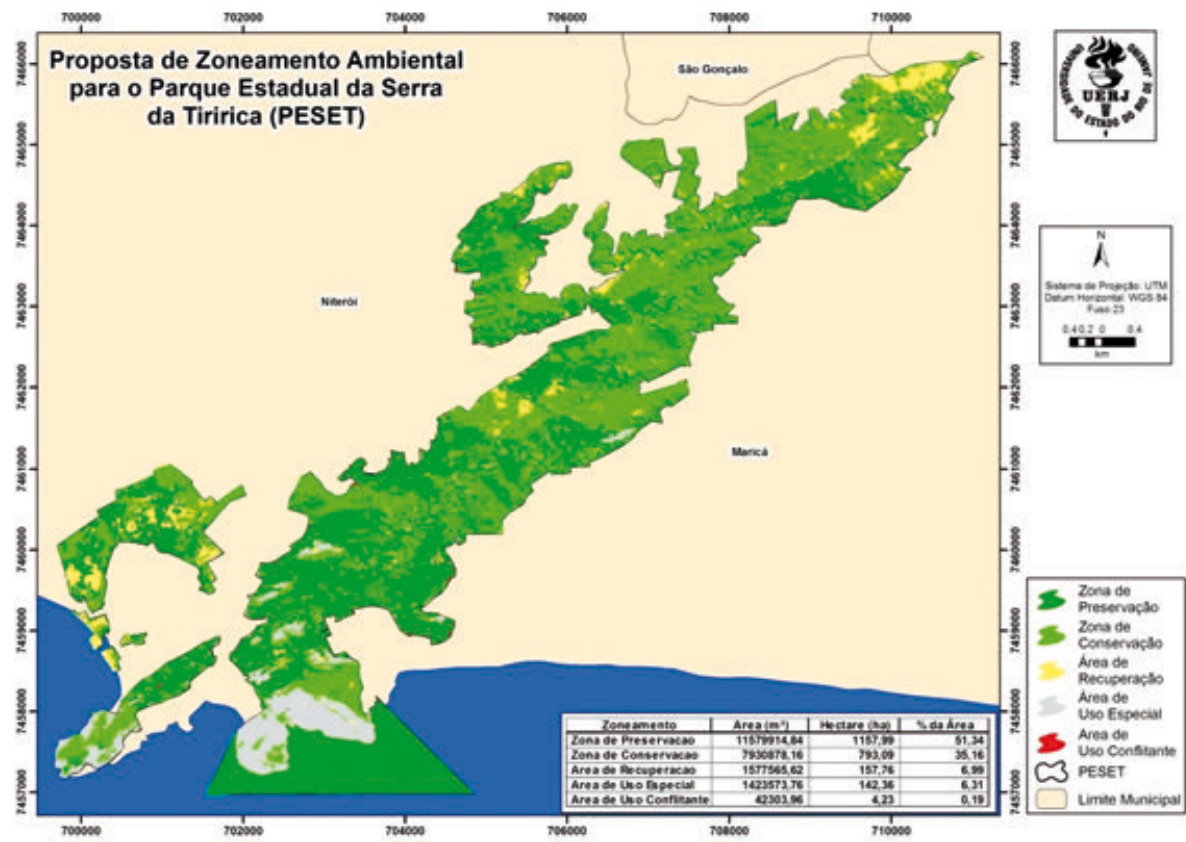

Figura 3 - Mapa de Zoneamento Ambiental.

\section{5 - Consideraçóes finais}

O presente artigo teve como objetivo demonstrar a importância do Sistema de Informação Geográfica (SIG) no auxílio aos estudos de uso da Terra e cobertura vegetal no Parque Estadual da Serra da Tiririca. A classificação obtida no SRING reforça a importância deste software para o processamento digital de imagens. A utilização do software ArcGIS, correspondeu a pós-classificação, tendo como fundamento a interpretação visual aliada ao reconhecimento das classes em campo, pois o conhecimento da área de estudo pelo intérprete se fez necessário para uma melhor avaliaçáo e apresentação dos resultados.

Em relação às áreas protegidas por lei, os impactos indesejáveis da ação do homem sobre os recursos naturais, associados ao modelo de desenvolvimento incompatível com a ética sustentável, tem se tornado cada vez mais visíveis. Assim, a necessidade de compreender a dinâmica dos recursos naturais, agora dominado pelas açôes antropogênicas, tem colocado o ambiente natural como objeto de estudo em diversas áreas do conhecimento humano, dentre as quais a Geomática.

Conhecer a distribuição geográfica dos recursos naturais, das ações antropogênicas e da dinâmica do uso da Terra e cobertura vegetal é elemento imprescindível 
para subsidiar o planejamento, o monitoramento e a gestáo ambiental. Com a contínua transformação do espaço geográfico, representado pelas mudanças no uso e cobertura da terra, o monitoramento dos recursos naturais tornou-se fundamental, na medida em que a base desses recursos é condição essencial ao desenvolvimento sustentável.

A comparação feita entre as imagens IKONOS e WORLDVIEW só foi possível mediante a uma reamostragem dos pixels da segunda uma vez que o tamanho do pixel poderia influenciar no cálculo comparativo e quantitativo entre as imagens. Através do trabalho de campo na área da pesquisa, pode-se validar e refinar a classificação obtida através do processamento digital. Apesar de serem sensores distintos com características espectrais diferentes, a pesquisa pode ser realizada devido a relação quantitativa que foi o foco comparativo entre as imagens.

No mapeamento de uso da Terra e cobertura vegetal, foi adotada uma classificação que pudesse ser compatível com a realidade do Parque. Convém dizer que a classificação é antes de tudo uma representação da realidade e nunca a mesma, reforçando a necessidade dos trabalhos de campo e do conhecimento da área de estudo no processo de agregação das classes, de modo a diminuir as disparidades entre a realidade e a modelagem obtida.

O mapa de Zoneamento Ambiental procurou demonstrar a importância de um ordenamento territorial compatível com a realidade encontrada no parque. Sabe-se da importância estratégica de um estudo capaz de apontar políticas territoriais compatíveis com a realidade de uma Unidade de Conservação. A partir dessa proposta a os tomadores de decisão, responsáveis pela gestão da Serra da Tiririca, poderão elaborar um plano de manejo que atenderá às necessidades do parque.

Dessa forma, considerando que as geotecnologias formam conjunto de tecnologias para a coleta, processamento, análise e disponibilização de informaçôes com referência espacial, sua utilização torna-se imprescindível para a tomada de decisóes no âmbito da gestão ambiental estratégica no Parque Estadual da Serra da Tiririca.

Diante disso, vale ressaltar a importância do Parque Estadual da Serra da Tiririca no contexto de Unidade de Conservaçáo da Natureza no Estado do Rio de Janeiro e por ser um parque criado a partir de apelos populares, frente ameaça da crescente especulaçáo imobiliária, necessita de uma gestão participativa entre o poder público e a sociedade.

Agradecimentos - À Universidade Estadual do Rio de Janeiro, ao Parque Estadual da Serra da Tiririca e ao Instituto Estadual do Ambiente do Rio de Janeiro (INEA).

\section{6 - Referências Bibliográficas}

BELTRÃO, M. (1978) - Pré-História do Rio de Janeiro. Rio de Janeiro: Ed. Forense- Universitária/SEEC-RJ. $274 \mathrm{p}$.

BINS, L. S.; FONSECA, L. M. G.; ERTHAL, G. J.; MITSUO, F. (1986) - Satellite Imagery Segmentation: A Region Growing Approach. In: Simpósio Brasileiro de Sensoriamento Remoto, (SBSR), 14-19 abril - Salvador.

CÂMARA, G. (1996) - Desenvolvimento de Sistemas de Informação Geográfica no Brasil: Desafios e Oportunidades 
CARVALHO, M.S., PINA, M.F. SANTOS, S.M. (2000) - Conceitos Básicos de Sistemas de Informação Geográfica e Cartografia Aplicada à Saúde.

RODRIGUES, C. R. (2004) - Uso de Geoprocessamento de Imagens e Sensoriamento Remoto como Subsídios para a Caracterização da Cobertura Vegetal e do Uso do Solo da Bacia Hidrográfica do Sistema Lagunar Piratininga - Itaipu / Niterói - RJ.

SANTOS, L. A. F. e LIMA, J. P. C. (1998) - Potencial Florístico do Parque Estadual da Serra da Tiririca. In: Floresta e Ambiente, Instituto de Florestas Universidade Federal Rural do Rio de Janeiro, Editora EDIL, V. $5, n^{\circ} 1$,

INEA - INSTITUTO ESTADUAL DO AMBIENTE (2010) - Roteiro metodológico para elaboração de planos de manejo: parques estaduais, reservas biológicas, estaçóes ecológicas - Rio de Janeiro / Brasil

SISTEMA NACIONAL DE UNIDADES DE CONSERVAÇÃO DA NATUREZA - SNUC (2000) - : lei n. 9.985, de 18 de julho de 2000; decreto n. 4.340, de 22 de agosto de 2002. 4a Edição. Brasília: MMA/ SBF. 2004.52 p. 